\title{
CON ELLOS SOLOS NO, PERO SIN ELLOS TAMPOCO: LOS PODEROSOS EN EL ORIGEN Y FORMACIÓN DE LAS INSTITUCIONES CENOBÍTICAS SEGÚN EL MONASTERIO JERÓNIMO CORDOBÉS DE VALPARAÍSO*
}

\author{
POR \\ SOLEDAD GÓMEZ NAVARRO ${ }^{1}$ \\ Universidad de Córdoba
}

\section{RESUMEN}

Partiendo del consenso historiográfico sobre el indudable peso e influjo de las élites laicas y eclesiásticas en la fundación de monasterios en la España Moderna, este trabajo, a través del específico pero muy significativo caso de los jerónimos cordobeses de Valparaíso, desvela cómo se produce concretamente aquel proceso, aportando un modelo al efecto desde la historia local -que no localista-, con el análisis de la familia impulsora y su acción a tal fin, e indicando los distintos factores que lo propiciaron.

PALABRAS CLAVE: Poderosos; fundaciones; monacato; jerónimos; España Moderna.

\section{WITH THEM ONLY NOT, BUT WITHOUT THEM ALSO: THE POWERFUL IN THE ORIGIN AND TRAINING OF THE CENOBYTIC INSTITUTIONS ACCORDING TO THE CORDOVAN JERONIMOS MONASTERY OF VALPARAISO}

\begin{abstract}
Starting from the historiographic consensus on the undoubted weight and influence of the lay and ecclesiastical elites in the foundation of monasteries in modern Spain, this work, through the specific but very significant case of the Cordovan Jeronimos of Valparaiso, reveals how concretely it occurs Process, providing a model for this effect from local history, not localist, with the analysis of the founding family and its action to that end, and focusing on the various factors that propitiated it.
\end{abstract}

KEY WORDS: Powerful; foundations; monastic; Jeronimos; Modern Spain.

Como CITAR ESTe ARtículo / Citation: Gómez Navarro, S. 2018. «Con ellos solos no, pero sin ellos tampoco: los poderosos en el origen y formación de las instituciones cenobíticas según el monasterio jerónimo cordobés de Valparaíso». Hispania Sacra 70, 142: 455-466. https://doi.org/10.3989/hs.2018.031

$\begin{array}{ll}\text { Recibido/Received } & \text { 05-01-2017 } \\ \text { Aceptado/Accepted } & \text { 06-02-2017 }\end{array}$

Como hace ya bastante tiempo señaló el añorado don Antonio Domínguez Ortiz, fue muy importante, a veces incluso inexcusable, el protagonismo e influencia de las élites - señoras y señores ricos y piadosos - en la creación

* Aportación realizada en el marco del Proyecto CSO2015-68441C2-2-P (MINECO/FEDER); así como sustancial ampliación con las consideraciones escuchadas en el foro en que intervine con la Ponencia inédita sobre la fundación cordobesa de esa orden típicamente ibérica como fue la jerónima, presentada por invitación en el I Congreso Internacional Os Jerónimos no Mundo Luso-Hispânico. História, Arte e Património, celebrado en Lisboa del 22 al 25 de julio de 2015 0950

hi1gonas@uco.es / ORCID iD: http://orcid.org/0000-0002-1962- del monacato femenino y masculino en la primera Edad Moderna y ya desde los siglos medievales. ${ }^{2}$ Ahí, insistiendo en el papel de aquellas en la fundación y conformación de monasterios y conventos de la España Moderna, han incidido después aportaciones importantes y aun decisivas al efecto, como las de Ángela Atienza López, ${ }^{3}$ Juan Jesús Bravo Caro, ${ }^{4} \mathrm{M}$ a del Mar Graña Cid, ${ }^{5}$ Jesús Pérez Morera, ${ }^{6} \mathrm{o}$

\footnotetext{
Domínguez Ortiz 1992: 71.

3 Atienza López 2008, 2009a y 2009b.

4 Bravo Caro 2009: 11.

5 Graña Cid 2011a y 2011b.

6 Pérez Morera 2005.
} 
Marion Reder Gadow, entre muchos otros que haría muy interminable esta lista, ${ }^{8}$ o la colectiva dirigida por el profesor Martínez Ruiz, ${ }^{9}$ pero, qué sabemos de ese proceso a nivel local, cómo contribuyeron las élites en casos concretos, $y$, sobre todo, qué sabemos de una forma exhaustiva y completa, más allá de los acercamientos puntuales, por lo demás siempre ciertamente meritorios, necesarios y de los que ha dado cuenta la academia en citas bien reconocidas. ${ }^{10}$

Partiendo del monasterio jerónimo cordobés de Valparaíso - uno de los primeros fundados en Andalucíadesde sus patrocinadores y patrimonio originario, pretendo responder a aquellas dos cuestiones, así como, desde una investigación local -que no localista-, proponer un modelo para esa temática en formas de promoción, instrumentos utilizados y recursos empleados; sin olvidar, por supuesto, los factores que lo propiciaron, desde luego el religioso-cultural, indudable en una sociedad altamente sacralizada como la española del Antiguo Régimen, en general, y de sus primeras centurias en particular, pero también naturalmente los económicos, sociales y políticos. Analicemos, pues, primero la familia fundadora y su papel en la llegada de los jerónimos a Córdoba, y luego la institución a través de su fundación y patrimonio originario, las dos partes que constituyen esta aportación, que abrochará una reflexión final sobre las motivaciones que la hicieron posible y permitieron.

LOS PROMOTORES-FUNDADORES DE VALPARAÍSO: LOS ALCAIDES DE LOS DONCELES

Las investigaciones sobre época medieval han revelado que el asentamiento en Córdoba, tras la reconquista efectuada por Fernando III en 1236, de los linajes Témez y Muñoz dará origen a la denominada "Casa de Córdoba», que durante los siglos bajomedievales estará en estrecha relación con la historia de la capital del califato y su Reino, de tal manera que la historia del linaje se confundirá con el ser de la ciudad y su territorio; así como que serán también los Fernández de Córdoba - así apellidados desde los últimos años del siglo XIII- los protagonistas de la fundación del monasterio jerónimo cordobés de Valparaíso, primer monasterio de varones creado, no sin las licencias del obispo y de la Orden, por la nobleza cordobesa, pues los existentes hasta el momento de su fundación habían sido dispuestos por la corona de Castilla o por iniciativa de las propias Órdenes, y, en concreto, la viuda de un nieto de Alfonso Fernández de Córdoba, primer titular del linaje, quien con la aprobación de su hijo, Martín Fernández de Córdoba (1382-1437), funde en 1408 este monasterio. Este hecho, el protagonismo de esta familia en la fundación y dotación primitiva de san Jerónimo, justifica el análisis de la historia

\footnotetext{
7 Reder Gadow 2000, entre otras muchas páginas que ha dedicado al monacato femenino y que simbolizamos, por lo concerniente específicamente al tema que nos ocupa, en la obra colectiva que coordinó en 1997 con motivo el III Centenario de la Fundación del Monasterio de Agustinas Recoletas de Cabra, en Córdoba, Reder Gadow 1999.

8 Un estado de la cuestión bastante completo en: Gómez Navarro 2011a: 205-206.

9 Martínez Ruiz 2004

10 Para el caso que nos ocupa indispensables, y entre otros, al menos éstos: Campos y Fernández de Sevilla 1995 y 1999.
}

familiar de la rama de este linaje que ostentará los títulos de Alcaides de los Donceles y, posteriormente de marqueses de Comares, aunque obviamente se analizarán en su relación con el monasterio jerónimo cordobés por haber sido los principales valedores de la comunidad jerónima cordobesa masculina, como digo, durante los dos primeros siglos de su existencia. ${ }^{11}$ No resulta fácil trazar los primeros pasos del linaje hasta llegar a la mitad del siglo XIV y encontrarnos con Diego Fernández de Córdoba I (1343-1371) y su esposa Inés Martínez -o Inés Martínez de Pontevedra, o Inés de Pontevedra, como también se la denomina-, fallecida en 1416 y la fundadora o promotora junto a su hijo Martín, de Valparaíso, pero marcaré los trazos principales.

Los primeros del linaje son Alfonso Fernández de Córdoba (1283-1327) y su hijo Fernán Alfonso de Córdoba (1327-1343). El primero es ejemplo de una carrera política y administrativa ascendiente y bien trabada. Comienza siendo alguacil mayor de Córdoba, cargo que, como todos sabemos, era concedido por los monarcas a un vecino destacado y que recibido, en su caso, de Sancho IV en agradecimiento al apoyo que su padre le había prestado en Córdoba durante la guerra civil con Alfonso $X$, le permitirá el dominio de Córdoba y su tierra, $y$, sobre todo, vincular así al linaje el alguacilazgo mayor, oficio que, ejercido por delegación real, tenía a su cargo el poder ejecutivo de la justicia administrada por los alcaldes, mantenía el orden público en la ciudad y su territorio y guardaba las llaves de la ciudad amurallada. Por su intervención en la conquista de Baena, Luque y Zuheros el concejo de Córdoba le entregó en señorío la villa y castillo asimismo cordobeses de Cañete aproximadamente a comienzos del siglo XIV; por casi esa misma fecha recibe la dehesa de Galapagar en la villa cordobesa de Pedroche y en 1310 el nombramiento de alcaide de la villa y castillo de Alcalá de los Gazules. Redondea su patrimonio al unir las prebendas indicadas a lo que había percibido como herencia paterna, esto es, el castillo y heredamiento de Dos Hermanas y más de cincuenta yugadas de extraordinaria tierra en la campiña de Córdoba y cercanías de la ciudad; y encumbra su propia carrera aumentando su influencia y poder al encomendársele el Adelantamiento Mayor de Frontera hacia 1313 con funciones gubernativas, administrativas, económicas, militares y jurisdiccionales en el territorio, anunciando así la futura labor de sus descendientes dentro del agitado, complicado y complejo mundo fronterizo. Casado con doña Teresa Jiménez de Góngora testó el 25 de octubre de 1327.

Su hijo, sucesor y heredero del mayorazgo paterno ya conformado - recordemos, Cañete, heredad de Paterna y dehesa de Galapagar-, Fernán Alfonso de Córdoba, continúa el engrandecimiento del patrimonio familiar y le sigue asimismo en la carrera político-militar y administrativa. Lo primero con la adquisición de ciertas compras como el cortijo de Don Lázaro, la casa de la Alhadra, la heredad del Choco en Ferrera, el heredamiento de Benasurera y unas casas en Córdoba, ${ }^{12}$ a lo que añade también las tercias de Cañete que le concede el rey en 1337. Lo segundo, con la participación en la batalla del Salado, muy activamente en la defensa de la frontera, y su puesto de alcaide de la

\footnotetext{
11 Nieto Cumplido 2012: 43-52. Sanz Sancho 1989.

12 Nieto Cumplido 2012: 44.
} 
villa jiennense de Alcaudete y de la villa cordobesa de Castro del Río. Herido en el cerco de Algeciras, fallecerá en Córdoba el 13 de diciembre de 1343, no sin antes dejar como descendientes de sus segundos esponsales con María Ruiz, hija de don Rodrigo Íñiguez de Biedma, a Gonzalo Fernández de Córdoba, señor de la casa de Aguilar; Diego Fernández de Córdoba, el iniciador de la rama del Alcaide de los Donceles - o niños que se habían criado en la Cámara del rey desde muy pequeños-, con la que precisamente arrancará el monasterio de Valparaíso, título no hereditario pero distintivo de esta rama durante los siglos XIV y XV hasta que reciban el de marqueses de Comares en 1512; Martín Fernández de Córdoba, y Alfonso Fernández de Córdoba, el menor, del que se originará la rama de la casa de Montemayor.

En efecto, desde 1343 se inician los antecedentes primeros de la fundación de Valparaíso, pues el ya citado Diego Fernández de Córdoba, alcaide de los Donceles y alguacil mayor de Córdoba, casará con Inés Martínez, fundadora de Valparaíso junto a su hijo Martín. Fiel a Pedro I y Enrique II la guerra civil entre éstos hizo que tomara partido por el último, lo que le permitirá recibir un juro anual de veinte mil maravedíes situados sobre las rentas de la alcabala vieja de las carnicerías de Córdoba, ${ }^{13}$ al que sumará ciertos bienes comprados como el lugar y castillo cordobés de Montalbán, o la villa de la Puebla de Chillón, entonces perteneciente al reino de Córdoba. Formado mayorazgo autorizado por Enrique II, testa el 9 de agosto de 1371, el mismo año de su fallecimiento, no sin antes fundar dos años antes capilla - la del Espíritu Santo- en la catedral cordobesa, en cuyo texto el cabildo se muestra sumamente "elogioso para el linaje y su propia persona», ${ }^{14}$ y desde luego «proporcionar a sus sucesores un señorío suficiente, que constituirá la base material sobre la que apoyar su linaje y su prestigio social». ${ }^{15}$ La relevancia de su matrimonio con doña Inés Martínez para la historia de Valparaíso obliga al menos a recordar la prosapia asimismo de ésta, al ser hija del tesorero mayor de Pedro I Martín Yáñez de Aponte o de Sevilla, y de su esposa doña Juana; que su patrimonio a la muerte de su esposo lo formarán los diez mil maravedíes del juro de la alcabala vieja de las Carnicerías, las rentas de La Alhadra, el usufructo de las casas principales de la familia en la collación cordobesa de san Nicolás de la villa, así como el monto de bienes no declarados del testamento materno, entre los que se hallaba la casa en que vivía doña Juana; y, por supuesto, la solidez del patrimonio y la posición social de su hijo y descendiente y el otro cofundador o patrocinador de Valparaíso, Martín Fernández de Córdoba, el alcaide de los Donceles, pues con él culmina la trayectoria de esta familia hasta el momento en que unan sus destinos a la llegada del monje jerónimo fray $\mathrm{B}(\mathrm{V})$ asco desde Portugal a Córdoba para erigir el monasterio de Valparaíso, y en los que jugarán papel fundamental sus enlaces familiares, como es lo habitual en la nobleza, pero también su propia trayectoria vital. ${ }^{16}$

13 Archivo Ducal de Medinaceli, Comares, secc. Lucena, leg. 3 (Inventario 1708).

14 Nieto Cumplido 2012: 45.

15 Quintanilla Raso 1979: 167

16 Soria Mesa 2000.
En cuanto a lo primero, muy importantes $-\mathrm{y}$ aun claves en la historia de Valparaíso- fueron, en efecto, sus dos matrimonios, el primero con doña María Alfonso de Argote, señora de Lucena y Espejo, de la que nacerían Diego Fernández de Córdoba, que le sucedería en el mayorazgo de Chillón, y Gonzalo Fernández, veinticuatro de Córdoba; y el segundo, con Beatriz de Solier - apellido de presumible origen francés-, y del que nacerían siete vástagos entre los que destacarían Alfonso de Córdoba, alcaide de los Donceles, y, sobre todo, Pedro de Solier, arcediano de Castro, primero, luego obispo de Córdoba entre 1464 y 1476 y especialmente gran benefactor de Valparaíso.

Por lo que respecta a la trayectoria vital de Martín Fernández de Córdoba, tres aspectos son singularmente relevantes: El pleito que debió afrontar por la posesión de Chillón, su presencia en el concilio de Constanza como delegado laico, y la misma administración y gestión del patrimonio familiar. ${ }^{17}$ Para la resolución del primer asunto vitales fueron las cartas de privilegio que recibió de Enrique III confirmatorias de la compra de Chillón, cuando fue molestado en su posesión, a principios del siglo XV, justo casi coincidiendo con la fundación de Valparaíso, por la demanda interpuesta por los condes de Alburquerque - don Fernando de Lara y la infanta doña Leonor - que le reclamaban la devolución de Chillón, vendido al alcaide de los Donceles Diego Fernández de Córdoba en tiempos y con autorización de Enrique II, aunque, finalmente, el 14 de abril de 1403 , los condes se apartaron de la demanda y Martín no solo pudo seguir en la posesión pacífica de su señorío, sino que, solo dos años después, colaborará activamente en la fundación del cenobio jerónimo cordobés con la donación de un pedazo de tierra calma y una huerta en Valparaíso, como veremos.

Destacable igualmente fue su participación y actuación como embajador de Castilla nombrado por Alfonso $\mathrm{V}$ en el decisivo concilio de Constanza (1414-1418) para la resolución del cisma de Occidente, y que le sitúan «en el momento más importante de su carrera política». ${ }^{18}$ Ello le permitirá codearse y compartir responsabilidad con otros altos representantes de la sociedad de la época, como el obispo de Cuenca don Diego de Anaya, el obispo de Badajoz Juan de Villalón, el antiguo confesor de Enrique III fray Fernando de Illescas, el deán de Sevilla y oidor Fernando Martínez Dávalos, o el deán de Palencia Diego Fernández de Valladolid, todos ellos acompañados, como secretario de sus actuaciones, por el arcediano de Grado en la catedral de Oviedo Pedro de la Guardia, personajes todos ellos tan destacados, ilustres y letrados entre los que se hallaba «aquel noble y valiente cordobés, elegido con aprobación de la reina Catalina de Lancaster ${ }^{19}{ }^{19}$ obtener de Martín V el 1 de enero de 1418 el privilegio, muy propio por otra parte de la mentalidad religiosa de la época, de asistir a los oficios divinos en su casa en tiempo de entredicho, indulgencia plenaria a la hora de la muerte para él y su esposa, elegir confesor durante su vida con las atribuciones de los penitenciarios menores, o indulgencia plenaria al fin de las vidas de varios parientes de su casa; y recibir de Juan

\footnotetext{
17 Nieto Cumplido 2012: 50-59.

18 Ibídem: 52.

19 Ibídem: 54.
} 
II el 22 de septiembre de 1418 la recompensa de cuarenta mil maravedíes de juro sobre las alcabalas de paños y carnicerías de Córdoba.

La última gran ocupación y preocupación de Martín Fernández de Córdoba, de este destacado representante de la nobleza local cordobesa y cofundador y copatrocinador del monasterio jerónimo cordobés junto a su madre, como ya sabemos, fue aumentar, sostener y llevar «el peso de la familia», como se ha dicho, ${ }^{20}$ ámbito en el que destaca la complicación del reparto de su herencia por su doble descendencia y, sobre todo, por la acción y maniobras de su segunda esposa al respecto, y que, a la postre, cumpliendo su testamento de 16 de julio de 1416, cuando ya llevan los jerónimos ocho años en Córdoba, conducirá al desmembramiento de los bienes vinculados por mayorazgo, en concreto de Lucena y Espejo, porque Martín Fernández de Córdoba deja a su primogénito del primer matrimonio, Diego Fernández de Córdoba, la primera villa citada, y al primogénito de su segundo enlace, Alfonso de Córdoba, el título de alcaide los Donceles y el señorío de la segunda villa con La Alhadra; quien, a su vez, instituirá por su heredero a su hermano, Pedro de Solier - o de Córdoba, como a veces también consta-, el futuro arcediano de Castro y luego obispo de Córdoba, como ya sabemos.

Llegamos así a este último personaje, don Pedro de Solier, hijo del alcaide de los Donceles Martín Fernández de Córdoba y nieto por ende de doña Inés Martínez -o Martínez de Pontevedra-, que tanto protagonismo, si bien al principio totalmente involuntario por ser muy tierno infante, tendrá en la historia, al menos más conocida, de la fundación de Valparaíso. También fue todo un personaje. Estudiante en Salamanca y Bolonia, clérigo y bachiller en decretos y doctor por la curia romana en tiempos de Eugenio IV, Pedro de Solier, obviamente asimismo un peso pesado de la élite nobiliaria cordobesa, pasa a los anales de la ciudad por su complicado gobierno como obispo de la diócesis al coincidir aquel con la guerra civil entre el infante-rey don Alfonso y su medio hermano Enrique IV, lo que dividió al cabildo catedralicio y, sobre todo, lo enfrentó, por doce años, con otro poderoso indiscutible de la Córdoba del momento como fue don Alonso de Aguilar, cabecilla de los partidarios notables locales del infante don Alfonso, con el que, sin embargo, firmará concordia al final de su prelatura, gestada, precisamente, en san Jerónimo y con la intermediación, como árbitros, de su prior, fray Antón de la Hinojosa, y su provisor, Ximén López de Valenzuela, que le permitirá recibir los bienes que le quitó indebidamente don Alonso y repartirlos entre "sus parientes» Alfonso de Córdoba y Pedro de Solier, que no eran otros que sus hijos, porque don Pedro no guardó durante su vida precisamente la continencia.

Como se ha visto, es indudable el peso y responsabilidad de los Fernández de Córdoba en la fundación y patrocinio del monasterio jerónimo cordobés de Valparaíso, con su acogimiento de los frailes portugueses que llegarán a Córdoba a principios del siglo XV -en 1405 exactamente, aunque el cenobio arranca oficialmente tres años después-, pero no menos fundamental fue la acción al efecto, atendiendo la petición de la familia de los Donceles y

\footnotetext{
20 Nieto Cumplido 2012: 57 y ss.
}

sin cuya licencia no se hubiera podido fundar el monasterio, del que ha sido denominado y considerado "obispo protector», es decir, del prelado cordobés entre 1398 y 1424 don Fernando González Deza. ${ }^{21}$ Un rápido repaso a su biografía lo dibujan como magnífico ejemplo asimismo de la élite y, sobre todo, prelado arquetípico: Ascendencia noble, protagonista indirecto de un trágico episodio en su infancia cuando su padre fue mandado matar junto con otros nobles por Pedro I después de tomar la villa cordobesa de Aguilar, de buena formación canónica en la Universidad de Salamanca, de carrera eclesiástica rápida y sólida copando oficios y dignidades importantes en los cabildos de Córdoba y Sevilla -maestrescuela en el primero, canónigo en el segundo-, diligente y correcto cumplidor de los encargos que ha ido recibiendo de sus cabildos, sobre todo de los de índole económica, cometido que le había permitido tomar posesión del diezmo del almojarifazgo cordobés, preocupado porque su renta estaba sin arrendar; próximo al cabildo y cordial con sus miembros; amante del conocimiento como iluminación del entendimiento y servicio a Dios y a los hombres por producir frutos espirituales y temporales; y conciliador y pacificador sobre todo en duros años de finales del siglo XIV cuando epidemias, revueltas ciudadanas, ataques a la judería y pobreza campan por doquier. $Y$ es en ese ambiente en el que precisamente se fragua la fundación de san Jerónimo de Valparaíso, tal vez como una forma de poder, tal vez, en la conocida crisis de la vieja Iglesia bajomedieval, como demanda espiritual a tanta inestabilidad social, como se ha interpretado. ${ }^{22} \mathrm{Y}$ es aquí, precisamente, donde enganchamos con la fundación de Valparaíso, como decimos, y, especialmente, donde tiene sentido preguntarse por qué en Córdoba y por qué con los Donceles.

Porque este prelado junto con doña Inés y don Martín serán los grandes promotores y munífices de san Jerónimo, pero ante la red de relaciones que establecieron, es más que probable suponer que en la fundación cordobesa de san Jerónimo jugó algo más que la fortuita circunstancia de que inmediatamente sanara el nieto de aquélla, el ya conocido y analizado don Pedro de Solier, el futuro obispo de Córdoba, en grave peligro de muerte en los brazos de su abuela cuando llegaron fray Vasco y fray Lorenzo, y de la mano de González Deza, buscando acomodo para instalarse en la feraz sierra cordobesa. El milagro como aval de la fundación está bien; su carácter providencialista, también, porque con la acción de fray Vasco, que no actúa por sí mismo, sino guiado y obrando por la llamada de Dios, el monasterio nacía por obra divina, no humana; la santidad de la obra, de la fundación, igualmente muy loable, y además garantizada porque sus principales promotores, el obispo González Deza y doña Inés son tenidas por personas virtuosas e irreprochables; y, por si fuera poco, se presenta como expresión de la reforma, pues los hijos de san Jerónimo buscan el aislamiento y huyen de la ostentación, la riqueza y la comodidad, por lo que representaban lo que ansiaban algunas minorías ante el espectáculo bochornoso y grave crisis de la Iglesia premoderna, esto es, volver a la sencillez y autenticidad del espíritu evangélico, en este

\footnotetext{
21 Ibídem: 108-119.
}

22 Ibídem: 116. 
caso del monacato, como una de las soluciones desde abajo ante aquella, como una expresión de reforma in capite et in membris que anhela sinceramente la grey, desconcertada pero fervientemente creyente y religiosa. ${ }^{23}$ Pero la rápida disponibilidad de las tres primeras heredades para la fundación cordobesa, el cúmulo de propiedades que poseía la familia - madre e hijo- en las cercanías de Córdoba, aun la rapidez de las decisiones, probablemente estén indicando relaciones personales o epistolares previas de doña Inés Martínez con fray Vasco o con algún otro monasterio jerónimo próximo a Lisboa o a Córdoba, como el de santa María de Guadalupe.

Porque, efectivamente $-y$ como se ha constatado-,${ }^{24}$ la nobleza cordobesa -en las personas de doña Leonor López de Córdoba, hija del maestre de Calatrava don Martín López de Córdoba; Inés Páez, hija de la linajuda familia cordobesa formada por Ximén Pérez de Bedmar y doña Urraca Venegas; el señor de Carcabuey Ruy Díaz de Berrio, o Diego Gutiérrez de los Ríos-, o personas vinculadas a oficios concejiles de la capital del califato o de sus villas, como el jurado cordobés Pero Díaz de Estepa, o el de la villa de Palma Domingo Martínez, ya estaban en relación con Guadalupe años antes de la fundación de Valparaíso con gestos como romerías, cumplimientos de promesas, o dejación de legados testamentarios, todo lo cual permite sostener, fundada y seriamente, que si fray Vasco y fray Lorenzo eran desconocidos para González Deza y doña Inés cuando llegan a Córdoba, su propuesta en modo alguno lo era ni para el primero ni para la segunda; y lo que asimismo se refuerza cuando en el documento de donación de los terrenos para el monasterio se lee que fray Lorenzo llega a Córdoba con poderes de fray Vasco, lo que parece, efectivamente, apuntar a que todo estaba acordado previamente.

Pero establecidos los quiénes, veamos ahora el cómo y el con qué se opera, o apartado segundo de esta contribución.

\section{LA FUNDACIÓN Y EL PATRIMONIO ORIGINARIO DE VALPARAÍSO}

Es el documento número uno con sus tres legajos del Libro Protocolo de San Jerónimo de Valparaíso elaborado por fray Fernando de Cáceres y Verlanga el que transmite el origen de Valparaíso en sus anotaciones de la llegada de Vasco de Sousa y la fundación del monasterio y sus propiedades iniciales, Huerta, Dehesilla, Córdoba la Vieja y Montes, la Dehesilla, fontanares, olivar y agua de la huerta de la Gitana, la hospedería y lo que percibía en especie, doce cahíces de pan terciado y veinticuatro fanegas de sal. El primer legajo recoge la fundación del monasterio y bienes originarios de huerta, dehesilla, Córdoba la Vieja y montes; el segundo consiste prácticamente todo en las anotaciones sobre la gestión de la Dehesilla, fontanares, olivar y agua de la huerta de la Gitana; y el tercero se dedica a los doce cahíces de pan terciado, veinticuatro fanegas de sal y la hospedería.

La fundación de Valparaíso, encabezada en aquél por una muy propia de la época invocación religiosa, como no podía ser por lo demás de otra forma a comienzos del siglo XV - «En el nombre del Todopoderoso, Dios en la esencia

\footnotetext{
23 Gómez Navarro 2016.

24 Nieto Cumplido 2012: 103-105.
}

uno, y en las personas trino, eterno, inmenso y soberano, causa y principio, sin principio, de todo lo criado, y de quien desciende y dimana todo bien, así espiritual, como temporal; de la siempre Virgen María, madre del mismo Dios, y siempre Señora nuestra, que fue concebida en gracia en el instante primero de su animación santísima; de su bienaventurado esposo, padre putativo de Cristo Señor Nuestro, el Señor san José; del Señor san Rafael Arcángel, mi especial patrono, y abogado; y del máximo doctor mi venerado Padre san Jerónimo. Comienzo a notar este Protocolo, con arreglo a los instrumentos de su archivo, por la fundación de este santo monasterio en el siguiente modo»- ${ }^{25}$ se concreta, como ya se ha adelantado en el análisis social de los promotores, en la decisión, en 1405, del jerónimo portugués fray Vasco de trasladarse del país vecino, donde ya había fundado dos conventos, a España para fundar también aquí cenobios jerónimos, para lo que envía como emisario a Córdoba a un discípulo suyo, fray Lorenzo, para que se entrevistase con el obispo, a la sazón Fernando González Deza -y no Rodríguez de Biedma, como indica el Libro Protocolo, y quizás de los pocos datos irreales de su contenido, porque no corresponden a documentación notarial, ni al obispo correcto en cuestión, que era, en efecto, González Deza, ${ }^{26}$ y error que podría obedecer a la copia de alguna "Historia de la Orden» como la de Sigüenza, por parte del amanuense correspondiente del Libro Protocolo-, ${ }^{27}$ quien le notifica que no tiene dónde ofrecerles que funde, pero sí le facilita el contacto de doña Inés Martínez, la ya conocida viuda de Diego Fernández, alcaide de los Donceles, y del hijo de ambos, don Martín Fernández, alcaide también de los Donceles y señor de la villa de Chillón, quien tenía diferentes posesiones libres y a la que visitarían para proponerle la empresa que pensaban acogería sin repulsa. Aquélla, una de las dos personas verdaderamente fundadoras del monasterio jerónimo cordobés junto a su hijo, pues fray Vasco fue solo el instrumento humano, ofreció dos posibles parcelas, lo que propiciaría la venida a Córdoba de fray Vasco acompañado de otros cuatro religiosos, fray Rodrigo, fray Pedro, fray Juan y fray Gomes, para la decisión final. Ésta cristaliza en el otorgamiento de la escritura de donación de cierta huerta que doña Inés tenía cerca de Córdoba la Vieja por aquélla y su hijo a favor de fray Lorenzo en voz y nombre de fray Vasco; en concreto, de un pedazo de tierra calma y huerta contigua a la ya expresada para dote y como dote de dicha fundación, en Córdoba, a 10 de mayo de 1405, ante el notario público apostólico Velasco Jiménez de Segovia; como condición a la donación se fija la obligación de cantar perpetuamente una capellanía. No podía empezar mejor ni tener mejores garantías de continuidad y mantenimiento un cenobio que comenzaba a funcionar por el apoyo de lo más egregio de la nobleza local, ${ }^{28}$ y cuya iniciativa pronto también sería emulada por otros poderosos locales y no locales, como se verá.

Rápidamente se produce la aceptación de la donación por los monjes recipiendarios $y$, en consecuencia, la

25 Gómez Navarro 2014: 192; 1999: 915 y ss.

26 Gracia Boix 1977: 36. Nieto Cumplido 2012: 108.

27 Gómez Navarro 2014: 192.

28 Nieto Cumplido 2012: 43-86. Proceder tanto en origen como en dotación inicial generalmente asimismo aplicado y seguido: Marín López 1995: 111-135, entre otros muchos casos. 
pronta realización de capilla, altar y coro para el culto; los religiosos citados y el obispo acuden al lugar donde debería erigirse el monasterio el 9 de julio de 1408 ante el notario apostólico Juan Lope y en el monasterio, pues es importante indicar que en este momento Valparaíso está bajo jurisdicción episcopal. Se nombra como primer prior a fray Vasco y los otros cuatro monjes profesos señalados como conventuales; se reitera la jurisdicción episcopal y se obtiene concesión de facultad o permiso del obispo para edificar iglesia mayor, campanario, claustro, dormitorio y todas las precisas oficinas de los demás monasterios e incluso cementerio: En definitiva, erección jurídica o institucionalización de san Jerónimo por el prelado quien, en magnífico ejemplo de lo que era teoría y práctica de lo que denominamos "espiritualización de bienes», exhortaba a todos los fieles del obispado que ya tuviesen a Valparaíso por monasterio de la orden de san Jerónimo y que «en remisión de sus pecados ayudasen con sus limosnas a los frailes de él». ${ }^{29}$ El nuevo monasterio empezaría pronto a llevar la denominación de «real», pero no por fundación, como importa mucho aclararse especialmente en el Libro Protocolo, ${ }^{30}$ sino por decisión de Juan II de Castilla, quien por su real cédula de 12 de noviembre de 1440 recibió a todos los monjes de este monasterio y a todos sus sirvientes, familiares y paniaguados «bajo de su amparo y protección, y bajo de su guarda, su seguro y defendimiento real», ${ }^{31}$ mandando que así por todos los sitios se pregonase y las justicias de su reino lo entendiesen, e imponiendo gravísimas penas a los contraventores de tal decisión; este privilegio lo reiterará Isabel de Castilla, de tal manera que cualquier agravio al monasterio sería considerado delito de lesa majestad, según recoge la real cédula emitida en Córdoba el 13 de diciembre de 1478; conjunción, pues, de ambas células es que a Valparaíso se le denomine "real», aun si haber sido tal su fundación. ${ }^{32}$

Las páginas iniciales de la fundación se completan con dos anotaciones importantes más, la primera de las cuales especialmente importante por lo tocante a la trayectoria posterior de Valparaíso: La concesión por Inocencio VIII en 1492 a sus monjes del "privilegio e indulto» de quedar «libres y exentos de la jurisdicción ordinaria de los señores obispos», y "que de esta regalía gozasen todas las cosas que por derecho o en otro cualquier modo les pertenezcan o pertenecer puedan ${ }^{33}$ mandándose el correspondiente aviso al obispo a la sazón de Córdoba; y el aumento creciente y sólido, y ya casi desde sus inicios, del monasterio, lo que propició el traslado de la iglesia de su lugar original, que en 1772 cuando se redacta el Libro Protocolo, servía de lavandería, al sitio donde en el Setecientos ya se hallaba, consagrándose la nueva por el obispo de San Juan de Puerto Rico, el agustino fray Fernando de Valdivia y Mendoza, el 15 de enero de 1719, y siendo obispo de Córdoba Marcelino Siuri; la ceremonia fue singularmente significativa para la orden jerónima por cuanto contó con la colocación bajo

29 Gómez Navarro 2014: 194.

30 Ibídem: 194-195.

31 Ibídem: 194.

32 Atienza López 2008: 97-150. De todas formas fue un monasterio muy favorecido, mimado, privilegiado y protegido desde sus inicios por el poder político y religioso: Gómez Navarro 2011b: 89 y ss.

33 Gómez Navarro 2014: 194. el ara del altar mayor de las reliquias de los mártires san Teodoro, san Leoncio y otros, para verificar en la osculación del ara al ingreso de la misa, y de ahí que desde aquel día se celebre anualmente la dedicación y consagración con rito de primera clase, y asistiendo a dicho acto prebendados y otras muchas personas de la mayor distinción, lo que prueba la alta consideración y estima de Valparaíso entre ese segmento de la población cordobesa aún en el siglo XVIII.

Respecto al patrimonio originario de la fundación de Valparaíso, caben varias observaciones iniciales.

Su contenido básico consistió fundamentalmente en ocho piezas diferentes que, sin embargo, el Libro Protocolo a veces unifica, a saber: La huerta cercada y contigua al monasterio, que es la donada por doña Inés Martínez, y a la que su hijo añade un pedazo de tierra calma y huerta y otra huerta más; la Dehesilla o haza de tierra calma que en aquél se empezará a conocer o denominar como dehesa de Córdoba la Vieja; los montes reales; la dehesilla, fontanares, olivar y agua de la huerta de la Gitana; los diezmos de las huertas y tierras junto al monasterio; ${ }^{34}$ los doce cahíces de pan terciado; las veinticuatro fanegas de sal, y las casas-hospedería, y, desde el principio, con todos los elementos suficientes para la explotación agropecuaria - agua abundante, por ejemploy la vida de la comunidad, como se ve.

La extensión del patrimonio primitivo u originario es generosa, pues sumando los nueve celemines y diecinueve fanegas de tierra de la huerta cercada y contigua al monasterio - sin las dos ermitas inclusas en aquélla-, las nueve ubadas y veinte estadales de la Dehesilla ${ }^{35}$ (o trescientas treinta y seis fanegas), ${ }^{36}$ y las setecientas cincuenta y una fanegas de Córdoba la Vieja y montes reales, se alcanzan las mil ciento seis fanegas de tierra, sin los cortijos que se incorporarían después. Cronológicamente el patrimonio original culmina prácticamente en la primera mitad del siglo XV, entre 14051408, fechas de la fundación-ocupación del monasterio, y 1459, como asimismo señalan los muy sólidos estudios para la época de Lora Serrano y Nieto Cumplido, ${ }^{37}$ con la sola excepción de la donación real de los montes de Córdoba la Vieja producida en 1605 . Jurídicamente, la figura dominante es la donación, con la sola salvedad de una venta por parte del cabildo catedralicio - en el caso de la Dehesilla - y una permuta, para la misma, con la colegiata de san Hipólito. Y la gestión fue combinada, presumiblemente directa para la huerta cercada y contigua al monasterio y la Dehesilla, por cuanto no constan documentos de arrendamientos, e indirecta, con éstos, para el resto del patrimonio.

En todo caso, las distintas anotaciones notariales desde el principio indican la disposición de Valparaíso de unas bases económicas originales muy bien dotadas para la explotación y la supervivencia, al ser muy rápidamente consolidado y privilegiado por poderosos significativos - aunque también concurrirán grupos populares, como sucederá en las

34 Sobre lo jugoso de este importante ingreso eclesiástico: Muñoz Dueñas 1988.

35 La ubada contiene treinta y seis fanegas, el estadal, como medida superficial o agraria, tiene dieciséis varas cuadradas y equivale a once metros, diecisiete decímetros y cincuenta y seis centímetros cuadrados.

36 Nieto Cumplido 2012: 307.

37 Lora Serrano 1982: 668 y ss.; Nieto Cumplido 2012: 104-107, respectivamente. 
atenciones a la hospedería, por ejemplo, pero también en otros asuntos de la comunidad jerónima-, lo que, de nuevo, señala el ya apuntado reforzamiento y garantía de permanencia del aquél; la pronta ampliación y redondeo del patrimonio contiguo al monasterio; la tendencia a la muy interesante concentración parcelaria como estrategia de explotación, también desde casi sus inicios; la inteligencia y el sentido empresarial en la gestión económica agraria, como asimismo se ha señalado; ${ }^{38}$ el uso de sistemas de explotación mixtos; y, sobre todo, la precoz presencia de conflictos y litigios con otras instituciones eclesiásticas y civiles, precisamente por la importancia y repercusión de algunas piezas del patrimonio originario. Veamos ahora el desmenuzamiento de todas estas primeras deducciones, indicando las vicisitudes o incidencias más destacadas en cada caso.

Así, en efecto, la huerta cercada y contigua al monasterio, cerca de Córdoba la Vieja, como se aclara, constaba de diferentes arboledas de olivar disperso y sin orden, de lima dulce y agria, limón, toronja, granada de tres calidades, naranja china, dulce y agria, higueras, ciruela y otros árboles frutales. En sus dos terceras partes esta huerta era de doña Inés Martínez, y son las partes donadas a los monjes fundadores. Fue el núcleo o base primera de Valparaíso, al que se añade la donación de don Martín Fernández, hijo de la antecedente, consistente en un pedazo de tierra calma y huerta, que estaban también en la anterior huerta, para que los monjes les aplicaran perpetuamente una capellanía cantada. Posteriormente, y por una escritura original en portugués, el alcaide de los Donceles e hijo de doña Inés Martínez, Martín Fernández, a instancia del padre fray Lorenzo derogó la carga de las dos capellanías perpetuas, con cuya condición el referido y su madre habían donado la referida huerta y otra tierra para fundar este monasterio, declarando que en lugar de dichas capellanías tuviesen tan solamente la obligación los religiosos que por tiempo fuesen de este dicho monasterio de rogar a Dios por los susodichos, cuya escritura se otorgó en la aldea portuguesa de la Gaviña a 21 de junio de 1438, ante el notario general del reino lusitano Alfón Pérez. Ambas donaciones de 10 de mayo de 1405. El mismo don Martín Fernández dona otra huerta que era suya propia, encima de Córdoba la Vieja, en 1412. Del obispo Fernando González Deza recibe Valparaíso, el 9 de agosto de 1419, la donación de los diezmos de las huertas y tierras que estaban junto a aquél para que los gozasen perpetuamente, como, efectivamente, así fue por cuanto cuando en 1772 se compila y redacta el Libro Protocolo, se escribe que "en cuya posesión está»; 39 en tanto que Gonzalo Ruiz, vicario de Montoro, vendió a Valparaíso un pedazo de tierra con sus árboles y agua y contiguo a las huertas del monasterio el 19 de mayo de 1422.

Por lo demás, importantes decisiones en este proceso inicial fueron las del concejo, justicia y regimiento de la ciudad de Córdoba, el 3 de diciembre de 1473, a los arrendadores y recaudadores de la renta del derecho de la fruta que se vendía, de que no llevasen derechos algunos a los religiosos ni criados de Valparaíso por las frutas que vendiesen de sus huertas, por estar exentos de pagar dicha imposición, tanto por el derecho común como por bulas apostólicas y reales privilegios; el vallado y cercado de las huertas, el 11 de abril de 1475, «en señal de dicha ratificación y nueva posesión»; ${ }^{40}$ y la provisión del Real Consejo, a instancias de los Reyes Católicos, de que dejasen en posesión a Valparaíso de la huerta cercada que éste tenía próxima a la fuente de los Berros, «por ser así voluntad de sus altezas»; ${ }^{41}$ el 9 de junio de 1492.

Entre los bienes de esta huerta se hallaban la dotación del agua de pie que producía una fuente de veinte pajas, una casa pequeña para el abrigo de los operarios, seis albercas, un molino para pan moler con piedra y albercón, y dos ermitas, una dedicada a nuestra Señora del Pilar y encima un triunfo a san Rafael, y otra dedicada a nuestra Señora de la Antigua, esto es $-\mathrm{y}$ como se-, toda la completa y diversificada infraestructura necesaria para la explotación y vivencia de una finca de explotación.

Por su parte, en cuanto a la Dehesilla, su llegada a Valparaíso se remonta al 30 de julio de 1456, cuando el deán y cabildo de la catedral de Córdoba vendió a Valparaíso una haza de tierra calma cerca de Córdoba la Vieja, linde ya por una parte con tierras del monasterio jerónimo, que de esta forma operaba por la antedicha concentración parcelaria, y de la que tomó posesión el monasterio al día siguiente. Por otra anotación del 3 de octubre de 1478 se la denomina haza de "santa María», apuntación en la que precisamente el licenciado Diego de Roxas, oidor de la Audiencia y juez de términos de Córdoba y obispado, consta haberle mandado a Sancho de Córdoba y a los veinticuatros de ella que no tuvieran por baldía la citada haza, como él creía, porque ha sido corregido por el monasterio, que le había presentado una escritura por donde constaba que la referida haza hacía veinte años que la había comprado al deán y cabido de la catedral. Finalmente, el 19 de julio de 1458 el obispo autorizó la permuta entre Valparaíso y los canónigos de la colegiata de san Hipólito por la que aquél dio a ésta siete casas en diferentes calles y parroquias por la dehesa y tierra calma que dichos canónigos tenían cerca de Córdoba la Vieja, que es la que ahora se comenta, tomando, efectivamente, Valparaíso posesión de ella diez días más tarde.

Esta propiedad sería problemática y contenciosa por sus linderos, por la presencia de los ganados del monasterio jerónimo en dehesa que el concejo de la ciudad entendía propia, y por considerarse a veces baldía.

Así, y en cuanto a los primeros, que eran con la dehesa de Cantarranas y con tierras de Aguilarejo y el camino de Sevilla, porque se apunta que unos memoriales conservados recogen el pleito planteado entre Valparaíso y el concejo de Córdoba por haberle quitado éste a aquél, injusta e indebidamente, un pedazo de tierras calmas que eran parte de la dehesa de Córdoba la Vieja que Valparaíso tuvo por la permuta con san Hipólito, y de la haza "santa María» que compró al cabildo catedralicio. El pleito se siguió en 1492, en cuyo 13 de junio el licenciado y juez de términos Sancho Sánchez de Montiel mandó quitar a Valparaíso dicho pedazo de tierra; se intentó reanudar el contencioso con más éxito para el monasterio en 1545, pero ante el empate de los cuatro abogados consultados, dos a favor de que Valparaíso

\footnotetext{
38 Martínez Ruiz 2004: 289 y ss.

39 Gómez Navarro 2014: 210.
}

\footnotetext{
40 Ibídem: 197.

41 ídem.
} 
continuara litigando aunque «estaba dudosa la justicia del dicho real monasterio", ${ }^{42}$ y los otros dos claramente en contra de su prosecución, se determinó por la comunidad no seguir dicho pleito, por lo que ganó el juez de términos, deslindándose de la dehesa de Cantarranas.

En cuanto al segundo problema, los Reyes Católicos solicitan al ya citado Sancho Sánchez de Montiel el 17 de enero de 1493 que permita a los monjes de Valparaíso que traigan sus ganados a la dehesa que el monasterio tenía en Córdoba la Vieja, sin impedirle la posesión en que estaba, y que la fuente llamada de los Berros, que aquel juez había declarado concejil, «no se tuviese por tal, con el cargo de que los religiosos la adobasen y no impidiesen que los vecinos aprovechase la que sobrase ; $^{43}$ la cuestión era, pues $-y$ como se ve-, el aprovechamiento y disponibilidad de los recursos básicos. Por lo relativo, finalmente, al tercer asunto, en 1544 el procurador de Valparaíso Juan Sánchez de Requena debió justificar ante el corregidor de Córdoba que las tierras propias del monasterio en Córdoba la Vieja no eran baldías, "como por parte del concejo de dicha ciudad de Córdoba se intentaba», ${ }^{44}$ por cuanto le pertenecían por escrituras otorgadas a su favor por los cabildos de la catedral y san Hipólito, como ya sabemos.

Por su parte, el uso por Valparaíso de la pieza de Córdoba la Vieja y Montes se remonta a la real cédula de 23 de julio de 1567 que permitía a la comunidad jerónima que llevase a pastar a la dehesa de Córdoba la Vieja doscientas cabezas de ganado menor, señalando el sitio en que no hiciesen daño a las yeguas y potros; en el mismo instrumento también se les permitía llevar por quince o veinte días todo el ganado que tuvieran durante el esquilo, y poder tener caleras y ladrilleras y cortar toda la leña y retama que necesitara el monasterio. Asimismo, otra real cédula de 30 de junio de 1570 permitía a Valparaíso traer a pastar a la dehesa de Córdoba la Vieja seis bueyes, con tal de que fuese en sitio que no perjudicase a las yeguas y potros de raza, y otra más de 17 de junio de 1583 mandaba al caballerizo mayor de las reales caballerizas que permitiese traer a la dehesa de Córdoba la Vieja doscientos carneros y doce bueyes de Valparaíso durante cuatro años; de esta forma Valparaíso pudo librarse de la doble denuncia que recibió el 30 de abril de 1622 sobre que habían estado pastando una noche en Córdoba la Vieja bueyes y carneros contra las ordenanzas del rey, al presentar las dos reales cédulas que autorizaban a pastar a Valparaíso en dicha dehesa, mandando, por tanto, el corregidor que no se procediese contra él ni contra sus ganados.

Por último, una real cédula del 23 de marzo de 1605 reconoce que hacía más de seis años que san Jerónimo había aceptado el cambio de un pedazo de tierra que lindaba con tierras de Córdoba la Vieja propias del rey por ser muy útiles para la cría y conservación de los potros, por otras tierras, también reales, que eran montuosas y muy dañosas para dicha cría de potros; el mismo instrumento jurídico mandaba asimismo al corregidor y jueces de Córdoba que no se entrometieran en los negocios que se pudiesen ofrecer a los dependientes de las reales caballerizas. La permuta indicada

\footnotetext{
42 Gómez Navarro 2014: 199

43 Ibídem: 200.

44 Ídem.
}

fue ratificada por Felipe IV el 9 de diciembre de 1650. El monasterio tomó posesión judicial de las tierras donadas por el rey «con declaración de ser privilegiadas, cerradas y auténticas» el 23 de febrero de 1651, ${ }^{45}$ amojonándose tales montes reales donados por el rey a Valparaíso el 23 de enero de 1634. Un día y siete años después otra real cédula de Felipe IV aprobaba un cambio y permuta por la que el rey, y en su nombre el caballerizo mayor, dio a Valparaíso un pedazo de tierra «linde con tierras de él y de la huerta de la Gitana», ${ }^{46}$ y que ya estaba apeado y deslindando, y los jerónimos cordobeses al rey la dehesilla de los Fontanares, linde con la dehesa de Cantarranas, el Ochavillo, Córdoba la Vieja y Aguilarejo, como consta de la escritura otorgada en Córdoba el 2 de abril de 1650, tomando posesión de ellas el 23 de febrero de 1651.

Evidencian la consolidación e importancia de esta pieza eclesiástica para Valparaíso dos medidas altamente importantes. Por un lado, la licencia solicitada por el monasterio jerónimo el 29 de mayo de 1743 al alcalde mayor de Córdoba "para romper las tierras calmas que están delante de este dicho monasterio», ${ }^{47}$ lo que parece indicar gestión directa de la misma. Por otro lado, la demanda asimismo de licencia por Valparaíso al cabildo de Córdoba para "cercar de piedra» la dehesilla de san Jerónimo, linde con el camino real alto de Sevilla, ${ }^{48}$ para obviar así los muchos perjuicios que se le seguían por no tenerla cercada, y así se hizo, amojonándose delante de un veinticuatro de la ciudad el 12 de abril de 1756, sin duda un paso más hacia la concentración y mejoramiento de la propiedad, y quizás adaptación y plasmación local de este tipo de medidas tan propias, por lo demás, de las mejoras revolucionarias agrarias del Setecientos. Y es que era muy importante esta pieza rústica para Valparaíso, y por eso también tuvo conflictos, en este caso con el convento cordobés de mínimos de san Francisco de Paula en su convento de nuestra Señora de la Victoria - por lo que el Libro Protocolo los denomina «victorios»-.

Así, consta la sentencia del juez de términos don Diego de Alvarado del 9 de agosto de 1674 también favorable a Valparaíso frente a los mínimos, que habían agregado al encinar que tenían lindando con la hacienda de Valparaíso un chaparral y doce fanegas y cuatro celemines de tierra calma que eran propios del monasterio jerónimo, multando además a «los victorios» al pago de doce mil maravedíes, «con apercibimiento de que si en adelante volvían a ocupar dichas doce fanegas y cuatro celemines de tierra,

45 Gómez Navarro 2014: 201. Más adelante en esta fuente se da un retroceso temporal y se indica que por otro instrumento autorizado por el escribano público cordobés Gonzalo de Toledo consta que a pedimento de este dicho real monasterio y de Pedro de las Infantas, por sí y en nombre de otros sus consortes criadores de ganados y vecinos de dicha ciudad, y en virtud de una real provisión de su majestad y señores de su real y supremo Consejo, el alcalde mayor mandó desbaratar los mojones que se habían puesto en la dehesa de Córdoba la Vieja, y que se les notificase a los guardas que allí estaban que saliesen y no guardasen dichas tierras y se quedasen libres para pasto común; todo lo cual consta haberse así practicado el 1 de abril de 1544 ante el dicho escribano público Gonzalo de Toledo.

46 Ibídem: 204.

47 Ibídem: 202.

48 Ídem. 
serían penados en quinientos ducados». ${ }^{49}$ Obviamente Valparaíso alegó que el chaparral y las referidas fanegas le pertenecían, pero el juez mandó que aquél pidiese sobre este asunto en justicia. También hubo problemas en esas tierras, en concreto en el Encinarejo de "los victorios», en 1678, porque contraviniendo lo anteriormente indicado por Alvarado, un fraile victorio «las estaba guardando como si fueran de su convento", ${ }^{50}$ de forma que al pastor del ganado de Valparaíso lo había echado fuera y a los carneros que guardaba los había maltratado y quitado un capote, incurriendo en las penas contenidas en la sentencia pronunciada por Alvarado. Finalmente, la información del Libro Protocolo sobre la dehesilla, fontanares, olivar - que empieza a denominarse de Vall (o Valle)hermoso a partir del Setecientos-, agua de la huerta de la Gitana gira totalmente en torno a su forma de explotación.

Como se recordará, completaban el patrimonio inicial de los monjes jerónimos de Valparaíso doce cahíces de pan terciado, veinticuatro fanegas de sal y la hospedería.

Respecto a los primeros, su origen se remonta a la donación del 26 de noviembre de 1423 a Valparaíso por el obispo Fernando González Deza, quien de su mesa episcopal detraía, en efecto, doce cahíces de pan terciado para que Valparaíso los cobrase anualmente y de forma perpetua en los diezmos y donadíos de los lugares de Almodóvar del Río y Posadas, "con declaración que hizo su ilustrísima de que los situaba para dote y mantenimiento cumplido de ese dicho monasterio, por cuanto le constaba no tener bastante los religiosos para él»; ${ }^{11}$ donación confirmada por Pío II en 1459, y por el obispo jerónimo cordobés Gonzalo de Illescas un año antes, el 31 de mayo exactamente. Sin embargo, en un momento determinado aquéllos dejaron de percibirse, momento que debió ser antes de 1492 cuando Inocencio VIII los dejó libres de la jurisdicción episcopal. En este sentido es especialmente significativa la última anotación de este apartado del Libro Protocolo que también habla de litigio y conflicto, al expresar que por un papel firmado por el padre fray Ignacio de Olias, el 15 de marzo de 1599, consta que el no haber puesto Valparaíso demanda a la mesa episcopal de Córdoba fue porque, cuando se dejó de cobrar el situado de los doce cahíces de pan terciado, estaban los monjes sujetos a la jurisdicción episcopal, por lo que no osaron demandarlos, y porque el trigo tenía muy poco precio en aquel tiempo, pues habiéndole dado en Almagro mil fanegas, las vendieron en dos mil reales de vellón, por lo que venía salir a dos reales la fanega..$^{52}$

Por lo concerniente a las veinticuatro fanegas de sal, Valparaíso estaba en la posesión de que los arrendadores y señoríos de la sal y salinas le diesen, «de tiempo inmemorial», ${ }^{53}$ anualmente un cahíz y medio de sal -las veinticuatro fanegas de que se habla-, como reza la escritura notarial de 1518 ante Gonzalo de Toledo. Esta posesión se confirmaría por dos instrumentos más: Un mandamiento por real cédula de Felipe Il el 31 de julio de 1567 a los administradores de las salinas de Córdoba y su término que de las veinticuatro fanegas de sal que de tiempo inmemorial daba Córdoba a Valparaíso y de las que le diera en adelante, no les llevasen derechos algunos, especificándose explícitamente el 14 de septiembre de 1593 que se cumpliese y llevase a efecto la real cédula y que se asentara en los libros reales, ${ }^{54}$ prueba de lo fundamental que era esta donación para el mantenimiento de la comunidad; y la petición, el 20 de octubre de 1620, por Valparaíso al Consejo de Hacienda de que se llevase a efecto ese privilegio, «para lo que se despachase sobrecarta imponiendo en ella graves penas a los contraventores». ${ }^{55}$ Como se ve, Valparaíso insiste en que se tenga presente y aplique este privilegio por su inexcusabilidad para la comunidad, lo que también explica que sea objeto de conflicto.

De ahí, el requerimiento de Valparaíso, el 23 de septiembre de 1621, a Pedro Junguito, administrador de las salinas pertenecientes a don Carlos de Arellano, sobre que en dichas salinas se le diesen las veinticuatro fanegas de sal, que de tiempo inmemorial se le estaban dando para el gasto de aquél y de sus sirvientes, sin pagar por ello derechos algunos en fuerza de la citada real cédula; la notificación al licenciado Diego de Valcazar, juez por el rey de la administración de las salinas de Córdoba y su partido, de una real cédula de Felipe III del 16 de junio de 1621, acerca de las veinticuatro fanegas de sal que de dichas salinas se daban en cada año al monasterio jerónimo cordobés, a lo que dicho licenciado respondió que la obedecía en toda forma y que estaba pronto y presto, como siempre lo había estado, a no llevar «dineros algunos a dicho real monasterio por las veinticuatro fanegas de sal referidas $» ;{ }^{56}$ y la orden del Consejo de Hacienda del 28 de julio de 1627, para extender y favorecer a Valparaíso lo que ya disfrutaban los monasterios de san Lorenzo el Real, san Bartolomé el Real y otros cenobios jerónimos, esto es, la gracia real de que no pagasen derechos algunos de la sal que hubiesen menester, que era las veinticuatro fanegas que anualmente recibían de las salinas, por las que, por tanto, no pagarían derechos algunos, recibiéndolas, pues, «libres sin cobrarles cosa alguna por ellas, si no es en el caso de que habiéndolas recibido, las vendiesen, porque entonces se habían de cobrar de las ventas ${ }^{57}$ Precisamente un albalá - carta o cédula real en que se concedía alguna merced, o se proveía otra cosa, o documento público o privado en que se hacía constar alguna cosa- despachado por la Junta de Millones el 14 de enero de 1630 mandaba que Valparaíso pagase las veinticuatro fanegas de sal, abonando por cada fanega cuatro reales por la propiedad, ante lo que Valparaíso suplica a Felipe III que mandase por sobrecarta que el señor de las salinas diese las veinticuatro fanegas de sal anuales al monasterio cordobés «sin llevar los cuatro reales que pedía por cada fanega por razón de la propiedad ${ }^{58}$ aunque en un alarde de honestidad, el redactor del Libro Protocolo escribe que por diferentes recibos consta haber cobrado Valparaíso cuarenta fanegas de sal en las salinas de Duernas en cada año a precio de dieciséis reales de vellón. No obstante, y por los testimonios acopiados, es claro que esta prebenda debió ser demostrada y perseguida continuamente, porque desde el 2 de noviembre de 1631 el prior de Valparaíso y otros diferentes religiosos y a cada uno in solidum podría

\footnotetext{
49 Gómez Navarro 2014: 202.

50 Ídem.

51 Ibídem: 210.

52 Ibídem: 211.

53 Ídem.
} 
comparecer ante el rey y señores de sus reales Consejos presentando el real privilegio que el monasterio tiene de aquél para que se le diesen veinticuatro fanegas de sal en cada año para el gasto de sus religiosos, y para que pidiesen que se guardase y cumpliese el contenido de dicho real privilegio, y sigue reclamando la misma entrega aún el 16 de agosto de 1689. Parece, pues, evidente que no fue fácil mantenerlo, como se deduce de una certificación dada por don Diego Felipe Montesinos en la última fecha indicada, por la que consta quedar en su poder una copia de autos a continuación de una real cédula y de un requerimiento que en virtud de ella se hizo por parte de Valparaíso, sobre que se le entregasen veinticuatro fanegas de sal en cada año, cuyos autos se siguieron ante el escribano público de Córdoba Pedro Jurado. ${ }^{59}$

Por último, las casas hospedería que Valparaíso recibió en la donación originaria de doña Inés Martínez también fueron sucesivamente ampliadas, consolidadas y fortalecidas a lo largo del siglo XV y primeros años del XVI. Pasos importantes en esa dirección se dan bien por donación al monasterio, bien por compras del monasterio.

En la primera vía, efectivamente, la ya citada decisión de la fundadora, el 24 de octubre de 1414 -a los seis años justos de la fundación del monasterio-, de dar a fray Vasco como primer prior y a los demás monjes que en adelante fueran, unas casas, las mismas que aún eran hospedería en 1772, como se dice cuando se redacta el Libro Protocolo, frente de la iglesia parroquial de san Nicolás de la Villa, "sin más carga ni obligación que el que rogasen a Dios nuestro Señor por su ánima y por las de sus difuntos" ${ }^{60}$ y de las que, en efecto, fray Vasco tomó real posesión; las donaciones realizadas por Mencía López, viuda de Pedro Alfón, el 14 de junio de 1421 de un pedazo de corral para que se incorporase a las casashospedería, así como por el veinticuatro de Córdoba Antón Cabrera, el 16 de marzo de 1481, de un pedazo de trascorral que tenía en las casas de su morada, que lindaban con las expresadas de la hospedería. En el segundo mecanismo para la expansión del patrimonio de Valparaíso estarían las ventas hechas al monasterio por Isabel Gómez -el 23 de octubre de 1436 y con licencia de su marido, de un pedazo de corral lindero con las referidas casas hospedería-, Antón Martínez de Quero -el 10 de febrero de 1477, de la cuarta parte de una casa en la collación de san Nicolás de la Villa que se agregó a dicha hospedería-, Jerónimo Quero -el 13 de mayo de 1477 , de otra cuarta parte de dichas casas hospedería-, Catalina Martínez -el 3 de enero de 1478, de otra cuarta parte de dichas casas declarando que otras dos cuartas partes eran ya del monasterio-, y por los esposos Fernán Martínez de Estepa y Mari Rodríguez -el 12 de julio de 1479 , de la última cuarta parte de dichas casas que están agregadas a las de la hospedería-. Ayudar a los gastos de su mantenimiento correría a cargo de otro magnate de la época, doña Catalina Fernández de Córdoba, marquesa de Priego, quien por un mandamiento del 25 de septiembre de 1517 establecía que el recaudador de su villa de Montilla diese anualmente a Valparaíso diez mil maravedíes para ayuda a los gastos de la hospedería. Repetidas cédulas de los marqueses de Priego y casa de Aguilar impelían a los administradores

\footnotetext{
59 Gómez Navarro 2014: 212-213.

60 Ibídem: 213.
}

de sus rentas de la villa de Montilla para que diesen en cada un año diez mil maravedíes para los gastos de dicha hospedería; cuya donación está repetidamente confirmada, como del traslado de las cédulas consta, sacado por el escribano público Rodrigo de Molina el 4 de mayo de 1613; y de una carta firmada por el dicho marqués de Priego en que confiesa esta memoria, manifiesta gran sentimiento de que no se haya cumplido, y ofrece cumplirla y hacer que su hijo la cumpla. ${ }^{61}$

A lo largo del siglo XVIII las casas-hospedería seguirían jugando importante papel en las estrategias de los jerónimos por mantenerlas para cuando bajaban a Córdoba - a ello quizás obedeciera la real provisión de Carlos III de 10 de octubre de 1767, estableciendo que no se hiciera novedad en las casas de hospedería con tal de que en adelante no se admitieran en ellas más religiosos que los que tenían, el primero con el título de procurador, y el segundo con el de arquero, y los religiosos que se fuesen a curar y aquéllos que por recreación se retirasen a dicha hospedería por el tiempo que le permitieran sus constituciones; se completaba esta real provisión con la aprobación real, muy propia de la religiosidad de la época, de que las fiestas de precepto pasara uno de los religiosos de Valparaíso a decir misa a las personas seglares a quienes tienen encargado el cultivo y labranza de sus cortijos y haciendas, volviendo a dormir al monasterio-, ${ }^{62}$ aunque, en esta ocasión, con otro vecino también bien conocido en Córdoba por su notoriedad, el hospital de Antón Cabrera.

Así, sabemos del cambio o permuta del 26 de febrero de 1723 entre Valparaíso y los patronos del hospital de Antón Cabrera sobre un pedazo de sitio de dicho hospital, que era un cuartillo bajo techado, por otro sin techar de dicha hospedería; el acuerdo del 17 de abril de 1730 entre Valparaíso y los patronos de dicho hospital de Antón Cabrera en razón del remanente de la paja de agua que tenía dicho hospital para que lo gozaran las casas hospedería del monasterio, dando éste a aquél en cada año cuarenta reales de vellón por vía de limosna; la venta el 24 de mayo de 1764 realizada por el alcalde mayor de Córdoba, en fuerza de remate por autos de concurso formado a los bienes de don Manuel Molero Cañas de Oro, a Valparaíso de unas casas principales contiguas a las de la hospedería en precio de cuarenta y ocho mil novecientos cuarenta y seis reales con veintidós maravedíes de vellón; y la ampliación de gracia para el disfrute de fuente y agua principal sobrante en calidad de remanente para el abasto de las casas hospedería de Valparaíso que lindan con dicho hospital, concedida el 28 de diciembre de 1771 por los patronos del hospital de Antón Cabrera con el título de la Purísima Concepción de nuestra Señora. Por lo demás, la necesidad de hallar acomodo cuando los jerónimos cordobeses se desplazaban de Córdoba por cualquier motivo, explican la decisión del 19 de julio de 1529 por la que Valparaíso vendió a Francisco Díaz Cerezo unas casas que tenía en Pedro Abad por diez mil maravedíes con la condición de que siempre que alguno o algunos de sus monjes fuesen a dicha villa, les habría de dar posada "y guisarles la comida sin llevarle por ello cosa alguna»; ${ }^{63}$ o la 
aceptación de la donación hecha por el jurado Diego Alfón de Gagete a Valparaíso, de unas casas en que vivía en la parroquial de santa Marina, para que en ellas se hospedasen los jerónimos cuando fuesen a Córdoba desde el monasterio, y para que en ellas se construyese un altar en el que poder celebrar misas, "el cual consta haberse hecho». ${ }^{64}$

He llegado al final del camino que me propuse al principio de esta aportación. El contenido básico del patrimonio originario de la fundación consistió fundamentalmente en ocho piezas rústicas diferentes como fueron la huerta cercada y contigua al monasterio, que fue la donada por doña Inés Martínez, y a la que su hijo añadió un pedazo de tierra calma y huerta y otra huerta más; la Dehesilla o haza de tierra calma que se empezará a conocerse o denominar como dehesa de Córdoba la Vieja; los montes reales; la dehesilla, fontanares, olivar y agua de la huerta de la Gitana; los diezmos de las huertas y tierras junto al monasterio; los doce cahíces de pan terciado; las veinticuatro fanegas de sal, y las casashospedería. Desde el principio, pues, elementos todos ellos más que suficientes para la explotación agropecuaria - agua abundante, por ejemplo, pero también tierras muy feracesy la vida de la comunidad. La extensión del patrimonio originario es generosa, pues sumando todas las extensiones posibles de solo aquel - esto es, sin los cortijos que se unirán después- y obviando las dos ermitas inclusas en la huerta cercada contigua al monasterio, superaban ampliamente las mil fanegas de buena tierra, como ya sabemos. $Y$ todo ello en un periodo de tiempo relativamente breve, pues se produce entre 1405-1408, años de la fundación-ocupación del monasterio, respectivamente, y 1459, con la sola excepción de la donación real de los montes de Córdoba la Vieja que se produce en los primeros años del Seiscientos; con la donación como instrumento jurídico dominante, salvo la compra al cabildo catedralicio de la Dehesilla, y una permuta, para ésta misma, con la colegiata cordobesa de san Hipólito; y la gestión combinada, presumiblemente directa para la huerta cercada y contigua al monasterio y la Dehesilla, lo que parece lógico por la proximidad al cenobio, e indirecta mediante arrendamientos para el resto del patrimonio fundacional.

Desde el principio, pues, bases económicas primitivas muy bien dotadas para que Valparaíso pudiera asumir su explotación y supervivencia, ayudado también, y asimismo desde su origen, por poderosos significativos que rápidamente se aprestaron a consolidarlo y privilegiarlo, secundados, igualmente con relativa rapidez, por grupos populares, como sucederá en las atenciones a la hospedería, por ejemplo, pero también en otros asuntos de la comunidad jerónima masculina cordobesa, lo que, de nuevo, indica su ya varias veces señalado reforzamiento y garantía de permanencia. Obviamente el territorio de Valparaíso, a cuyo origen fundacional y patrimonio inicial hemos asistido, se completa con las figuras fundamentales de su correspondiente organigrama político-administrativo sin el que tampoco puede hablarse de institución propiamente dicha, y que hacen del Padre General, prior, vicario, procurador, juez apostólico conservador y monje apoderado figuras inexcusables por su importancia y funciones, siendo singularmente axiales el procurador y el juez apostólico

\footnotetext{
64 Gómez Navarro 2014: 215.
}

conservador por asumir, respectivamente, la administración de todos los bienes externos del monasterio, o defenderlo en los muchos y variados pleitos que surcaron su historia.

Queda así constituido el monasterio jerónimo cordobés de Valparaíso como institución, esto es, con territorio, patrimonio originario y administración; el tiempo irá ampliándolo con no pocas decisiones importantes sobre adquisición y gestión, como sabemos que sucedió. ${ }^{65}$ Pero en todo ese proceso fue clave la familia notable local promotora, como hemos visto, a la que, por cierto, pronto también se sumarán otras más, poderosas y no poderosas -o no tanto, en un interesantísimo proceso de emulación o mímesis social, quizás también de integración social一, como ha tratado de mostrar esta aportación que, con contenido o sustento local -que no localista, como dije al principio-, ha tenido sin embargo intención global para servir, como primer paso, de posible guía a la historiografía comparada especializada al efecto en relación a las formas de operar por los magnates para erigir, dotar y mantener cenobios; en los instrumentos jurídicos elegidos para ello; en los bienes aprontados, o en la implicación con un estamento también privilegiado como fue el eclesiástico - en concreto las órdenes regulares monacales-. En definitiva, abriendo caminos y marcando pautas de actuación, una forma más de ejercer poder político, social y cultural. No podía empezar mejor ni tener mejores garantías de continuidad y mantenimiento un cenobio que comenzaba a funcionar por el apoyo de lo más egregio de la nobleza local,,66 y cuya iniciativa pronto también sería continuada por otros poderosos locales y no locales, como muestran las dotaciones por testamentos y otros documentos de última voluntad, y erecciones de capellanías y memorias pías. ${ }^{67}$

En definitiva, y como planteaba al principio, un ejemplo para poder conocer si se opera así o no en otros lugares. Quizás este monasterio jerónimo cordobés de Valparaíso sea un buen caso para iniciar esas otras indagaciones y, sobre todo, para comparar. En cuanto a los factores que lo propiciaron, es evidente que el factor "providencial» cultural - por la sanación del nieto de la fundadoraparece incuestionable, como ya se indicó y se habrá notado, y como cabría esperar de una sociedad tan fuertemente clericalizada, sacralizada y sacramentalizada como la española del Antiguo Régimen, en especial de sus primeras centurias, e incluso por el seguimiento del gesto de constitución y dotación de una casa jerónima masculina en Córdoba por otros poderosos e incluso no tan poderosos de la ciudad - esa capacidad de emulación asimismo antes indicada-; pero es también indudable que operaron, y mucho, para tal instalación y su compacta y sólida consolidación, la vinculación de la fundadora-promotora de la venida de los jerónimos a la capital del Califato con su obispo cordobés contemporáneo, así como los factores económicos, sociales y políticos existentes, de alianzas fuertes y estrechas entre poderosos laicos y eclesiásticos, sin las que todo aquel proceso, bastante rápido y seguro por cierto como digo, tampoco hubiese sido posible.

65 Ibídem: 79-113.

66 Nieto Cumplido 2012: 43-86. Proceder tanto en origen como en dotación inicial generalmente asimismo aplicado y seguido: Marín López 1995: 111-135, entre otros casos.

67 Gómez Navarro 2014: pp. 129-154. 


\section{BiBLIOgRAFÍA}

Atienza López, Á. 2008. Tiempos de conventos. Una historia social de las fundaciones en la España Moderna. Madrid: Marcial Pons Historia.

Atienza López, Á. 2009a. «Fundaciones y patronatos conventuales y ascenso social en la España de los Austrias», en E. Soria Mesa; J. J. Bravo Caro (eds.), Las élites en la época Moderna: la Monarquía Española, IV: Cultura: 37-53. Córdoba: Universidad.

Atienza López, Á. 2009b. «Nuevos títulos, nuevos conventos en la España de los Austrias», en E. Soria Mesa; J. J. Bravo Caro (eds.), Las élites en la época Moderna: la Monarquía Española, IV: Cultura: 55-65. Córdoba: Universidad.

Bravo Caro, J. 2009. «El parecer y pertenecer a las élites de la edad Moderna. Ascenso social y fuentes para su estudio», en E. Soria Mesa; J. J. Bravo Caro (eds.), Las élites en la época Moderna: la Monarquía Española, IV: Cultura: 9-17. Córdoba: Universidad.

Campos y Fernández de Sevilla, J. (coord.). 1995. Monjes y monasterios españoles. El Escorial: Instituto Escurialense de Investigaciones Históricas y Artísticas.

Campos y Fernández de Sevilla, J. 1999. La Orden de San Jerónimo y sus monasterios. El Escorial: Real Instituto Escurialense de Investigaciones Históricas y Artísticas.

Domínguez Ortiz, A. 1992. La sociedad española en el siglo XVII. II: EI estamento eclesiásticos. Granada: Universidad-CSIC.

Gómez Navarro, S. 1999. "La orden de San Jerónimo y sus monasterios», en J. Campos y Fernández de Sevilla (coord.), La orden de San Jerónimo y sus monasterios, 2: 915-926. El Escorial: Rea Instituto Escurialense de Investigaciones Históricas y Artísticas.

Gómez Navarro, S. 2011a. «De rejas adentro: monjas y religiosas en la España Moderna. Una historia de diferencias en la igualdad». Revista de Historia Moderna: Anales de la Universidad de Alicante 29: 205-228.

Gómez Navarro, S. 2011b. «Bajo las alas del poder: gracias, mercedes y privilegios de los reyes españoles a los jerónimos cordobeses durante el antiguo régimen". Espacio, tiempo y forma. Serie IV. Historia moderna 24: 89-114.

Gómez Navarro, S. 2014. Mirando al cielo sin dejar el suelo: Los jerónimos cordobeses de Valparaíso en el Antiguo Régimen. Estudio Preliminar y Edición Crítica del libro Protocolo de la comunidad. Madrid: Visión Libros-Colegio Notarial de Andalucía-Real Instituto Escurialense de Investigaciones Históricas y Artísticas.

Gómez Navarro, S. 2016. Reforma y renovación católicas (ss. XVI y XVII). Madrid: Síntesis.
Gracia Boix, R. 1977. El Real Monasterio de San Jerónimo de Valparaíso en Córdoba. Córdoba: Real Academia de Córdoba.

Graña Cid, M. del M. 2011a. «Políticas nobiliarias femeninas y espiritualidad en la primera Edad Moderna. Santa Clara de Montilla». Verdad y Vida 258/LXIX: 149-177.

Graña Cid, M. a del M. 2011b. «Autoría femenina y carisma religioso. Orígenes de las clarisas descalzas en Andalucía». Estudios Franciscanos 112: 173-206 [También publicado en J. A. Echeverría (coord.), Historia magistra vitae: miscelánea de estudios en homenaje a Tarsicio de Azcona, OFMCap., historiador: 187-221. Pamplona: Hermanos Menores Capuchinos-Convento de Extramuros].

Lora Serrano, G. 1982. «El dominio del monasterio de San Jerónimo de Valparaíso (Córdoba)» en La España Medieval, II: Estudios en memoria del profesor D. Salvador de Moxó: 667-690. Madrid: Universidad Complutense.

Marín López, R. 1995. «La dotación fundacional del Monasterio de San Jerónimo de Granada», en J. Campos y Fernández de Sevilla (coord.), Monjes y Monasterios Españoles, II: Fundaciones e Historias Generales, Personajes, Demografía histórica: 111-135. El Escorial: Real Instituto Escurialense de Investigaciones Históricas y Artísticas.

Martínez Ruiz, E. (dir.). 2004. El peso de la Iglesia. Cuatro siglos de órdenes religiosas en España. Madrid: Actas.

Muñoz Dueñas, M.a D. 1988. El diezmo en el obispado de Córdoba (1750-1845). Córdoba: Publicaciones del Monte de Piedad y Caja de Ahorros.

Nieto Cumplido, M. 2012. El monasterio de San Jerónimo de Valparaíso. Córdoba: Almuzara.

Pérez Morera, J. 2005. "Renunciar al siglo: Del claustro familiar al monástico. La funcionalidad social de los conventos femeninos». Revista de Historia Canaria 20: 159-188.

Quintanilla Raso, C. 1979. Nobleza y señoríos en el reino de Córdoba: la Casa de Aguilar (siglos XIV y XV). Córdoba: Monte de Piedad y Caja de Ahorros de Córdoba.

Reder Gadow, M. (coord.). 1999. Actas del Congreso sobre «La Andalucía de finales del siglo XVII». Conmemorativo del III centenario de la Fundación del Monasterio de Agustinas Recoletas de Cabra. Cabra: Ilustrísimo Ayuntamiento, Excma. Diputación de Córdoba, Obra Cultural de Cajasur.

Reder Gadow, M. 2000. «Las voces silenciosas de los claustros de clausura». Cuadernos de historia moderna 25: 279-338.

Sanz Sancho, I. 1989. La Iglesia y el obispado de Córdoba en la Baja Edad Media (1236-1426). Madrid: Universidad Complutense.

Soria Mesa, E. 2000. El cambio inmóvil: transformaciones y permanencias en una élite de poder (Córdoba, ss. XVI-XIX). Córdoba: Posada. 